\title{
Documentación
}

\section{Discurso de agradecimiento en la recepción del Premio Nobel de Literatura}

\section{Harold Pinter \\ Reino Unido}

En 1958, escribí lo siguiente:

No hay grandes diferencias entre realidad y ficción, ni entre lo verdadero y lo falso. Una cosa no es necesariamente verdad o mentira; puede ser al mismo tiempo verdad y mentira.

Creo que estas afirmaciones todavía tienen sentido, y todavía tienen validez al explorar la realidad a través del arte. Así que, como escritor, las mantengo, pero como ciudadano no puedo hacerlo. Como ciudadano he de preguntar: ¿qué es verdad?, ¿qué es mentira?

La verdad en el arte dramático es siempre esquiva. Uno nunca la encuentra del todo, pero su búsqueda llega a ser compulsiva. Claramente, es la búsqueda lo que motiva el empeño. Tu tarea es la búsqueda. De vez en cuando, te tropiezas con la verdad en la oscuridad, chocando con ella o capturando una imagen fugaz o una forma que parece tener relación con la verdad, muy frecuentemente sin que te hayas dado cuenta de ello. Pero la auténtica verdad es que en el arte dramático no hay tal cosa como una verdad única. Hay muchas. Y cada una de ellas se enfrenta a la otra, se alejan, se reflejan entre sí, se ignoran, se burlan la una de la otra, son ciegas a su mera existencia. A veces, sientes que tienes durante un instante la verdad en la mano para que, a continuación, se te escabulla entre los dedos y se pierda.

Me han preguntado con frecuencia cómo nacen mis obras teatrales. No sé cómo explicarlo. Como tampoco puedo resumir mis obras, a menos que explique qué ocurre en ellas. Esto es lo que dicen. Esto es lo que hacen. 
Casi todas las obras nacen de una frase, una palabra o una imagen. A la palabra le sigue rápidamente una imagen. Pondré dos ejemplos de dos frases que aparecieron en mi cabeza de la nada, seguidas por una imagen, seguidas por mí.

Las obras son The Homecoming y Old Times. La primera frase de The Homecoming es "¿Qué has hecho con las tijeras?". La primera frase de Old Times es "Oscuro". En ninguno de los casos, disponía de más información.

En el primer caso, alguien estaba, obviamente, buscando unas tijeras y preguntaba por su paradero a otro de quien sospechaba que, probablemente, las había robado. Pero, de alguna manera, sabía que a la persona interrogada le importaban un bledo tanto las tijeras como el interrogador.

En Old Times tomé la descripción del pelo de alguien, el pelo de una mujer, y era la respuesta a una pregunta. En ambos casos, sentí la compulsión de continuar. Ocurrió visualmente, en una muy lenta gradación de sombra a la luz.

Siempre comienzo una obra llamando a los personajes A, B y C.

En la obra que acabaría convirtiéndose en The Homecoming, vi a un hombre entrar en una habitación austera, haciendo la pregunta a un hombre más joven, sentado en un feo sofá con un periódico de carreras de caballos. De alguna forma, sospechaba que A era un padre y que B era su hijo, pero no tenía la certeza. Esta posibilidad se confirmaría, sin embargo, poco después, cuando B (que más adelante se convertiŕa en Lenny) le dijera a A (más adelante convertido en Max): "Papá, ¿te importa si cambiamos de tema de conversación? Te quiero preguntar algo. Lo que cenamos antes, ¿cómo se llama? ¿Cómo lo llamas tú? ¿Por qué no te compras un perro? Eres un chef de perros. De verdad. Crees que estás cocinando para perros". De manera que como B llama a A "papa", me pareció razonable asumir que eran padre e hijo. A era claramente el cocinero y su comida no parecía ser muy valorada. ¿Significaba esto que no había una madre? Eso aún no lo sabía. Pero, como me dije a mí mismo entonces, nuestros principios nunca saben de nuestros finales.

"Oscuro". Una gran ventana. Un cielo al atardecer. Un hombre, A (que se convertiría en Deeley), y una mujer, B (que luego sería Kate), sentados con unas bebidas. “ ¿Gorda o flaca?”, pregunta el hombre. ¿De quién hablan? Pero entonces veo, de pie junto a la ventana, a una mujer, C (que sería Anna), iluminada por una luz diferente, de espaldas a ellos, con el pelo oscuro.

El momento de crear unos personajes, que hasta ese momento no han existido, es un momento extraño. Todo lo que sigue es irregular, vacilante, incluso alucinatorio, aunque a veces puede ser una especie de avalancha imparable. La situación del autor es rara. De alguna manera, no es bienvenido por los personajes. Los personajes se le resisten, no es fácil convivir con ellos, son imposibles de definir. Desde luego, no puedes mandarles. Hasta un cierto punto, puedes jugar 
una partida interminable con ellos, al gato y al ratón, a la gallina ciega, al escondite. Pero finalmente, encuentras que tienes en tus manos a personas de carne y hueso, personas con voluntad y con sensibilidad propia, hechos de partes, que eres incapaz de cambiar, manipular o distorsionar.

Asi que el lenguaje en el arte es una ambiciosa transacción, arenas movedizas, un trampolín, un estanque helado, que se puede abrir bajo tus pies, los del autor, en cualquier momento.

Pero, como he dicho, la búsqueda de la verdad no se puede detener nunca. No puede aplazarse, no puede retrasarse. Hay que hacerle frente, ahí mismo, en el acto.

El teatro político presenta problemas totalmente distintos. Hay que evitar los sermones a toda costa. Lo esencial es la objetividad. Hay que dejar a los personajes que respiren por su propia cuenta. El autor no ha de confinarlos ni restringirlos para satisfacer sus propios gustos, disposiciones o prejuicios. Ha de estar preparado a acercarse a ellos, desde una variedad de ángulos, desde un surtido amplio y desinhibido de perspectivas. Tal vez, de vez en cuando, cogerlos por sorpresa, pero a pesar de todo, dándoles libertad para ir a donde deseen. Esto no siempre funciona. Y, por supuesto, la sátira política no obedece a ninguno de estos cánones. De hecho, hace precisamente lo contrario, lo cual es su auténtica función.

En mi obra The Birthday Party, creo que permito que se abra un amplio abanico de opciones, en un denso bosque de posibilidades, antes de concentrarme, finalmente, en un acto de dominación.

Mountain Language no aspira a tal amplitud de posibilidades. Es brutal, breve y desagradable. Pero, en la obra, los soldados sí se divierten con ello. Uno a veces olvida que los torturadores se aburren fácilmente. Necesitan reírse de vez en cuando para mantener el ánimo. Este hecho ha sido confirmado, naturalmente, por lo que ocurrió en Abu Ghraib, en Bagdad. Mountain Language sólo dura veinte minutos, pero podría continuar durante horas, una y otra vez, podria repetirse lo mismo, siempre de nuevo, de forma continua, una y otra vez, hora tras hora.

Ashes to Ashes, por otra parte, me da la impresión de que transcurre bajo el agua. Una mujer que se ahoga, su mano que emerge sobre las olas, intentando alcanzar algo, que se hunde y desaparece, buscando a otros, pero sin encontrar a nadie, ya sea por encima o por debajo del agua, encontrando únicamente sombras, reflejos, flotando; la mujer es una figura perdida, en un paisaje que está siendo cubierto por las aguas, una mujer incapaz de escapar de la catástrofe, que parecla que sólo afectaba a otros. Pero, de la misma forma que ellos murieron, ella también ha de morir.

El lenguaje político, tal como lo usan los políticos, no se adentra en ninguno de estos territorios, dado que la mayoría de los políticos, según la evidencia a la 
que tenemos acceso, no están interesados en la verdad, sino en el poder, y en conservar ese poder. Para conservarlo es necesario mantener al pueblo en la ignorancia, que viva sin conocer la verdad, incluso la verdad sobre su propia vida. Lo que nos rodea es un enorme entrarnado de mentiras, de las cuales nos alimentamos.

Como todos sabemos, la justificación de la invasión de Irak era que Sadam Hussein tenía en su posesión un peligrosísimo arsenal de armas de destrucción masiva, algunas de las cuales podían ser lanzadas en $\mathbf{4 5}$ minutos, capaces de provocar una espeluznante destrucción. Nos aseguraron que eso era cierto. No era cierto. Nos contaron que Irak mantenía una relación con Al Quaeda y que era en parte responsable de la atrocidad que ocurrió en Nueva York, el 11 de septiembre de 2001. Nos aseguraron que esto era cierto. No era cierto. Nos contaron que Irak era una amenaza para la seguridad del mundo. Nos aseguraron que era cierto. No era cierto.

La verdad es algo completamente diferente. La verdad tiene que ver con la forma en la cual Estados Unidos entiende su papel en el mundo y cómo decide encarnarlo.

Pero antes de volver al presente, me gustaría mirar al pasado reciente, me refiero a la política exterior de Estados Unidos, desde el final de la segunda guerra mundial. Creo que es nuestra obligación someter esta época a cierto escrutinio, aunque sea de forma incompleta, que es todo lo que nos permite el tiempo que tenemos.

Todo el mundo sabe lo que ocurrí en la Unión Soviética y en toda la Europa del este, durante el periodo de posguerra: brutalidad sistemática, múltiples atrocidades, persecución sin piedad del pensamiento independiente. Todo ello ha sido ampliamente documentado y verificado.

Pero lo que pretendo mostrar es que los crímenes de Estados Unidos durante esa misma época, sólo han quedado registrados de forma superficial, no digamos ya documentados, o admitidos, o reconocidos siquiera cómo crímenes. Creo que a esto hay que ponerle fin y que la verdad sobre este asunto tiene mucho que ver con la situación en la cual se encuentra el mundo actualmente. Aunque limitadas hasta cierto punto por la existencia de la Unión Soviética, las acciones de Estados Unidos a lo ancho y largo del mundo dejaron muy claro que había llegado a la conclusión de que tenía carta blanca para hacer lo que quisiera.

La invasión directa de un Estado soberano nunca ha sido el método favorito de América. En la mayoría de los casos, han preferido lo que han descrito como "conflicto de baja intensidad". Conflicto de baja intensidad significa que miles de personas mueren, pero más lentamente que si se lanza una bomba sobre ellos de una sola vez. Significa que se infecta el corazón del país, que se implanta un tumor maligno y se observa cómo se desarrolla la gangrena. Cuando el pueblo 
ha sido sometido -o molido a palos, lo que viene a ser lo mismo- y tus propios amigos, los militares y las grandes corporaciones, se sientan confortablemente en el poder, te pones frente a la cámara y dices que la democracia ha prevalecido. Esto fue lo normal en la política exterior de Estados Unidos, durante los años de los cuales estoy hablando.

La tragedia de Nicaragua fue un ejemplo muy significativo. La recuerdo aquí como poderosos ejemplo de cómo ve América su papel en el mundo, tanto entonces como ahora.

Estuve presente en una reunión en la embajada de Estados Unidos en Londres, a finales de la década de 1980.

El Congreso de Estados Unidos estaba a punto de decidir si dar más dinero a la contra para su campaña contra el Estado de Nicaragua. Era un miembro de una delegación que venía a hablar en nombre de Nicaragua, pero la persona más importante en esta delegación era el padre John Metcalf. El líder del grupo estadounidense era Raymond Seitz (por aquel entonces, ayudante del embajador, más tarde, él mismo seŕa embajador). El padre Metcalf dijo: "Señor, estoy encargado de una parroquia en el norte de Nicaragua. Mis feligreses construyeron una escuela, un centro de salud, un centro cultural. Vivíamos en paz. Hace unos pocos meses, un grupo de la contra atacó la parroquia. Lo destruyeron todo: la escuela, el centro de salud, el centro cultural. Violaron a las enfermeras y a las maestras, asesinaron a los médicos, de la forma más brutal. Se comportaron como salvajes. Por favor, exija que el gobiemo de Estados Unidos retire su apoyo a esta repugnante actividad terrorista".

Raymond Seitz tenía muy buena reputación como hombre racional, responsable y altamente sofisticado. Era muy respetado, en los círculos diplomáticos. Escuchó, hizo una pausa, y entonces, habló con gravedad. "Padre", dijo, "déjeme decirle algo. En la guerra, la gente inocente siempre sufre". Hubo un frío silencio. Lo miramos. No parpadéo.

La gente inocente, en realidad, siempre sufre.

Finalmente, alguien dijo: 'Pero en este caso, 'las personas inocentes' fueron las víctimas de una espantosa atrocidad, subvencionada por su gobiemo, una entre muchas. Si el Congreso concede a la contra más dinero, ocurrirán más atrocidades como éstas. ¿No es así? ¿No es, por tanto, su gobierno culpable de apoyar actos de asesinato y destrucción contra los ciudadanos de un Estado soberano?".

Seitz se mantuvo imperturbable. "No estoy de acuerdo con que los hechos tal como han sido presentados apoyen sus afirmaciones", dijo.

Mientras abandonábamos la embajada, un funcionario estadounidense me dijo que había disfrutado con mis obras. No le respondí. 
Debo recordarles que en ese momento, el presidente Reagan hizo la siguiente declaración: "La contra es el equivalente moral de nuestros padres fundadores".

Estad́os Unidos apoyó la brutal dictadura de Somoza, en Nicaragua, durante 40 años. El pueblo nicaragüense, guiado por los sandinistas, derrocó este régimen, en 1979, una impresionante revolución popular.

Los sandinistas no eran perfectos. Tenían un claro componente de arrogancia y su filosofía política contenía una cierta cantidad de elementos contradictorios. Pero eran inteligentes, racionales y civilizados. Se propusieron conseguir una sociedad estable, decente y plural. La pena de muerte fue abolida. Cientos de miles de campesinos pobres fueron librados de una muerte segura. A unas 100,000 familias se le dieron títulos de propiedad sobre tierras. Se construyeron dos mil escuelas. Una notable campaña educativa redujo el analfabetismo en el país, a menos de una séptima parte. Se establecieron un sistema educativo y un servicio de salud gratuitos. La mortalidad infantil se redujo en una tercera parte. La polio fue erradicada.

Estados Unidos denunció estos logros como una subversión marxista-leninista. Desde el punto de vista del gobierno de Estados Unidos, se estaba estableciendo un ejemplo peligroso. Si a Nicaragua se le permitía fijar normas básicas de justicia social y económica, si se le permitía subir los niveles de salud y educación y alcanzar una unidad social y respeto nacional, los palses vecinos se plantearfan las mismas cuestiones y harian lo mismo. En ese momento, había por supuesto una feroz resistencia al status quo en El Salvador.

He hablado antes de "un entramado de mentiras", que nos rodea. El presidente Reagan describía habitualmente a Nicaragua como un "calabozo totalitario". Esto fue aceptado, en general, por los medios, y por supuesto, por el gobiemo británico, como comentario acertado e imparcial. Pero la realidad es que la existencia de escuadrones de la muerte, durante el gobiemo sandinista, no estaba documentada. No había constancia de torturas. No estaba probada la existencia de una brutalidad sistemática u oficial, por parte de los militares. Ningún sacerdote fue asesinado en Nicaragua. De hecho, había tres sacerdotes en el gobiemo, dos jesuitas y un misionero Maryknoll. Los calabozos totalitarios estaban, en realidad, muy cerca, en El Salvador y en Guatemala. Estados Unidos había hecho caer, en 1954, al gobierno elegido democráticamente, en Guatemala, y se estima que unas 200,000 personas habían sido víctimas de las sucesivas dictaduras militares.

Seis de los más eminentes jesuitas del mundo fueron asesinados brutalmente en la Universidad Centroamericana, en San Salvador, en 1989, por un batallon del regimiento Atlacatl, entrenado en Fort Benning, Geogia. Ese hombre extremadamente valiente, el arzobispo Romero, fue asesinado mientras se dirigía a la gente. Se estima que murieron 75,000 personas. ¿Por qué fueron asesinadas? Fueron asesinadas porque creían que una vida mejor era posible y que debía 
conseguirse. Esta creencia los convirti6, de inmediato, en comunistas. Murieron porque se atrevieron a cuestionar el status quo, la situación de pobreza, enfermedad, degradación y opresión sin fin, que habían recibido como herencia.

Finalmente, Estados Unidos hizo que cayera el gobiemo sandinista. Supuso varios años y una resistencia considerable, pero una persecución económica implacable y 30,000 muertos terminaron por minar la moral del pueblo nicaragüense. Exhaustos y condenados a la pobreza una vez más. Los casinos volvieron al país, la salud y la educación gratuita se acabaron. Las grandes empresas volvieron, en mayor número. La "democracia" había prevalecido.

Pero esta "política" no estaba restringida, en modo alguno, a Centroamérica. Fue puesta en práctica a lo largo y ancho del mundo. No tenía final. Y ahora es como si nunca hubiese ocurrido.

Estados Unidos apoyó, y en algunos casos creo, todas las dictaduras militares de derechas, en el mundo, tras el final de la segunda guerra mundial. Me refiero a Indonesia, Grecia, Uruguay, Brasil, Paraguay, Haití, Turquía, Filipinas, Guatemala, El Salvador, y, por supuesto, Chile. Nunca se podrá purgar, ni olvidar el horror que Estados Unidos implantó en Chile, en 1973.

Cientos de miles de muertes tuvieron lugar, en todos estos países. ¿Tuvieron lugar? ¿Son todas esas muertes atribuibles a la política exterior estadounidense? La respuesta es sí, tuvieron lugar y son atribuibles a la política exterior estadounidense. Pero ustedes, claro, no lo sabrán.

Eso nunca ocurrió. Nunca ocurrió nada. Ni siquiera ocurría mientras estaba ocurriendo. No importaba. No era de interés. Los crímenes de Estados Unidos han sido sistemáticos, constantes, inmorales, despiadados, pero muy pocas personas han hablado de ellos. Esto es algo que hay que reconocerle. Ha manipulado, clínicamente, el uso del poder, en todo el mundo, pretendiendo ser una fuerza al servicio del bien universal. Ha sido un brillante ejercicio de hipnosis, incluso ingenioso, y con un gran éxito.

Les digo que Estados Unidos es, sin duda, el mayor espectáculo ambulante que existe. Puede ser brutal, indiferente, desdeñoso y bárbaro, pero también es muy inteligente. Como vendedor no tiene rival, y la mercancía que mejor vende es el amor propio. Es un gran éxito. Escuchen a todos los presidentes de Estados Unidos en la televisión, usando las palabras, "el pueblo americano", como aparece en la frase, "le digo al pueblo americano que es la hora de rezar y defender los derechos del pueblo americano y le pido al pueblo americano que confien en su presidente, en la acción que va a tomar, en beneficio del pueblo americano".

Es una estratagema brillante. El lenguaje se usa hoy en día para mantener controlado al pensamiento. Las palabras "el pueblo americano" producen un cojIn de tranquilidad verdaderamente sensual. No necesitas pensar. Simplemente 
échate sobre el cojín. El cojín puede estar sofocando tu inteligencia y tu capacidad crítica, pero es muy cómodo. Esto no funciona, por supuesto, para los $\mathbf{4 0}$ millones de personas que viven bajo la línea de pobreza, ni para los dos millones de hombres y mujeres prisioneras en los vastos "gulags" de las cárceles, que se extienden a lo largo de todo Estados Unidos.

Estados Unidos ya no se preocupa por los conflictos de baja intensidad. No ve ningún interés en ser reticente o disimulado. Pone sus cartas sobre la mesa sin miedo, ni favor. Sencillamente, no le importa un bledo Naciones Unidas, la legalidad internacional o el desacuerdo crítico, que juzga impotentes e irrelevantes. Tiene su propio perrito faldero, acumucado detrás de él, la patética y supina Gran Bretaña.

¿Qué le ha pasado a nuestra sensibilidad moral? ¿Hemos tenido una alguna vez? ¿Qué significan estas palabras? ¿Se refieren a un término muy raramente utilizado estos días -conciencia? ¿Una conciencia para usarla no sólo con nuestros propios actos, sino para usar también con nuestra responsabilidad compartida, en los actos de los demás? ¿Está todo muerto? Miren a Guantánamo. Cientos de personas detenidas sin cargos, a lo largo de tres años, sin representación legal, ni juicio adecuado, técnicamente detenidos para siempre. Esta estructura totalmente ilegal persiste como desafío a la convención de Ginebra. Esto no es sólo tolerado, sino que difícilmente es planteado por lo que se llama "la comunidad internacional".

Esta atrocidad criminal está siendo cometida por un país, que se declara a sí mismo "el líder del mundo libre". ¿Pensamos en los habitantes de la bahía de Guantánamo? ¿Qué es lo que dicen los medios? Lo reseñan ocasionalmente - una pequeña mención en la pagina seis. Han sido consignados a una tierra de nadie de la cual, por cierto, puede que nunca regresen. En la actualidad, muchos están en huelga de hambre, alimentados a la fuerza, incluidos los residentes británicos. No hay sutilezas en estos procesos de alimentación. Ni sedaciones, ni anestésicos. Sólo un tubo insertado en tu nariz y dentro de tu garganta. Vomitas sangte. Eso es tortura. ¿Qué ha dicho la secretaría británica de exteriores sobre esto? Nada. ¿Qué ha dicho el primer ministro británico sobre esto? Nada ¿Por qué? Porque Estados Unidos ha dicho: criticar nuestra conducta en la bahía de Guantánamo constituye un acto poco amistoso. O están con nosotros o contra nosotros. Así que Blair se calla.

La invasión de Irak ha sido un acto de bandidos, un evidente acto de terrorismo de Estado, el cual muestra un desprecio absoluto por el concepto de leyes internacionales. La invasión fue una acción militar arbitraria, basada en una serie de mentiras sobre mentiras y una burda manipulación de los medios y, por consiguiente, del público; un acto con la intención de consolidar el control económico y militar de Estados Unidos sobre Oriente Medio, que fue disfrazado, como ultimo recurso, de liberación, cuando todas las otras justificaciones han caído por sí mismas. Una formidable demostración de fuerza militar, responsable de la muerte y mutilación de cientos y cientos de personas inocentes. 
Hemos llevado tortura, bombas cluster, uranio empobrecido, innumerables actos de muerte aleatoria, miseria, degradación y muerte para el pueblo iraquí y lo llamamos "llevar libertad y democracia a Oriente Medio". ¿Cuánta gente tienes que matar antes de que te consideren como un asesino de masas y un criminal de guerra? ¿Cien mil? Más que suficiente, habría pensado yo. Por eso, es justo que Bush y Blair sean procesados por el Tribunal Penal Internacional. Pero Bush ha sido listo. No ha ratificado el Tribunal Penal Internacional. Por eso, si un soldado o político americano es arrestado, Bush ha advertido que enviaría a los marinos. Pero Tony Blair ha ratificado el Tribunal y puede ser procesado. Podemos proporcionarle al Tribunal su dirección, si está interesado. Es el número 10 de Downing Street, Londres.

La muerte, en este contexto, es irrelevante. Ambos, Bush y Blair, colocan la muerte bien lejos, en los números atrasados. Al menos 100,000 iraquíes murieron, por causa de bombas y misiles americanos, antes de que comenzase la insurgencia iraquí. Estas personas ya no existen. Sus muertes no existen. Son espacios en blanco. $\mathrm{Ni}$ siquiera han sido registradas como muertas. "No hacemos recuento de cuerpos", dijo el general americano Tommy Franks.

Al inicio de la invasión, se publicó, en la portada de los periódicos británi$\cos$, una fotografía de Tony Blair, besando la mejilla de un niño iraquí. "Un niño agradecido", decía el pie de foto. Unos días después, en una página interior, aparecí́ una historia con una fotografia de otro niño de cuatro años sin brazos. Su familia había sido alcanzada por un misil. Él fue el único superviviente. “¿Cuando recuperaré mis brazos?", preguntaba. La historia desaparecí́. Bien, Tony Blair no lo tenía en sus brazos, tampoco el cuerpo de ningún otro niño mutilado, ni el de ningún cadáver ensangrentado. La sangre es sucia. Ensucia tu camisa y tu corbata, cuando te encuentras pronunciando un discurso sincero en televisión.

Los dos mil americanos muertos son una vergüenza. Son transportados a sus tumbas en la oscuridad. Los funerales son discretos, fuera de peligro. Los mutilados se pudren en sus camas, algunos para el resto de sus vidas. Así, los muertos y los mutilados se pudren, en diferentes tipos de tumbas.

He aquí un extracto del poema de Pablo Neruda: "Explico algunas cosas":

Y una mañana todo estaba ardiendo

y una mañana las hogueras

salían de la tierra

devorando seres,

y desde entonces fuego,

pólvora desde entonces,

y desde entonces sangre.

Bandidos con aviones y con moros,

bandidos con sortijas y duquesas,

bandidos con frailes negros bendiciendo 
venían por el cielo a matar niños,

y por las calles la sangre de los niños

- corría simplemente, como sangre de niños.

Chacales que el chacal rechazaría, piedras que el cardo seco mordería escupiendo, ¡víboras que las viboras odiarfan!

¡Frente a vosotros he visto la sangre de España levantarse para ahogaros en una sola ola de orgullo y de cuchillos!

Generales traidores:

mirad mi casa muerta, mirad España rota:

pero de cada casa muerta sale metal ardiendo en vez de flores, pero de cada hueco de España sale España, pero de cada niño muerto sale un fusil con ojos, pero de cada crimen nacen balas que os hallarán un día el sitio del corazón.

Preguntaréis ¿por qué su poesía no nos habla del sueño, de las hojas, de los grandes volcanes de su país natal?

Venid a ver la sangre por las calles, venid a ver la sangre por las calles, ¡venid a ver la sangre por las calles!

Quisiera dejar claro que, citando el poema de Neruda, no estoy comparando de ninguna manera la república española con el Irak de Saddam Hussein. Cito a Neruda porque en ningún otro sitio de la lírica contemporánea, he leído una descripción más poderosa y visceral del bombardeo contra civiles.

He dicho antes que Estados Unidos está ahora siendo totalmente franco al poner las cartas sobre la mesa. Éste es el caso. Su política oficial es, hoy en día, definida como "Dominio sobre todo el espectro". No son palabras mías. Son sus palabras. "Dominio sobre todo el espectro" quiere decir control de la tierra, del mar, del aire, del espacio y de todos sus recursos. 
Estados Unidos ahora ocupa 702 bases militares, a lo largo del mundo, en 132 palses, con la honorable excepción de Suiza, por supuesto. No sabemos muy bien cómo ha llegado a estar ahí, pero de hecho, ahí está.

Estados Unidos posee ocho mil cabezas nucleares activas y usables. Dos mil están en sus disparaderos, alerta, listas para ser lanzadas en quince minutos, después de una advertencia. Está desarrollando nuevos sistemas de fuerza nuclear, conocidos como "destructores de búnkeres". Los británicos, siempre cooperadores, están intentando reemplazar su propio misil nuclear, Trident. ¿A quién, me pregunto, están apuntando? ¿A Osama Bin Laden? ¿A tí? ¿A mí? ¿A Joe Dokes? ¿China? ¿París? ¿Quién sabe? Lo que sí sabemos es que esta locura infantil - la posesión y uso en forma de amenazas de armas nucleares - es el corazón de la actual filosofía política de Estados Unidos. Debemos recordamos a nosotros mismos que Estados Unidos está en un continuo entrenamiento militar y no muestra indicios de aminorar el paso.

Muchos miles, si no millones, de personas en el propio Estados Unidos están demostrablemente enfermas, avergonzadas y enfadadas por las acciones de su gobiemo, pero, tal y como están las cosas, no son una fuerza política coherente - todavía. Pero la ansiedad, la incertidumbre y el miedo que podemos ver crecer cada día en Estados Unidos, no es probable que disminuyan.

Sé que el presidente Bush tiene algunos escritores de discursos muy competentes, pero yo también quisiera presentarme como voluntario para el empleo. Propongo el siguiente discurso breve que él podría leer a la nación, en televisión. Lo veo solemne, con el pelo cuidadosamente peinado, serio, confiado, sincero, con frecuencia seductor, a veces empleando una sonrisa irónica, curiosamente atractiva, un auténtico macho.

Dios es bueno. Dios es grande. Dios es bueno. Mi Dios es bueno. El Dios de Bin Laden es malo. El suyo es un mal Dios. El Dios de Saddam también era malo, aunque no tuviera ninguno. El era un bárbaro. Nosotros no somos bárbaros. Nosotros no cortamos las cabezas de la gente. Nosotros creemos en la libertad. Dios también. Yo no soy bárbaro. Yo soy el líder democráticamente elegido de una democracia amante de la libertad. Somos una sociedad compasiva. Electrocutamos de forma compasiva y administramos una compasiva inyección letal. Somos una gran nación. Yo no soy un dictador. Él lo es. Yo no soy un bárbaro. Él lo es. Y él lo es. Todos ellos lo son. Yo tengo autoridad moral. ¿Ves mi puño? Esta es mi autoridad moral. Y no lo olvides.

La vida de un escritor es extremadamente vulnerable, apenas una actividad desnuda. No tenemos que llorar por ello. El escritor hace su elección y queda atrapado en ella. Pero es cierto que estás expuesto a todos los vientos, alguno de ellos, en verdad helados. Estás sólo, por tu cuenta. No encuentras refugio, ni protección - a menos que mientas - en cuyo caso, por supuesto, te habrás construido tu propia protección y, podría decirse, te habrás vuelto un político. 
Esta tarde, me he referido un par de veces a la muerte. Voy a citar ahora un poerna mío, llamado "Muerte".

¿Dónde se halló el cadáver?

¿Quién lo encontró?

¿Estaba muerto cuando lo encontraron?

¿Cómo lo encontraron?

¿Quién era el cadáver?

¿Quién era el padre o hija, o hermano

o tlo o hermana o madre o hijo

del cadáver abandonado?

¿Estaba muerto el cuerpo cuando fue abandonado?

¿Fue abandonado?

¿Por quién fue abandonado?

¿Estaba el cuerpo desnudo o vestido para un viaje?

¿Qué le hizo declarar muerto al cadáver?

¿Fue usted quien declaró muerto al cadáver?

¿Cuán bien conocía el cadáver?

¿Cómo sabía que estaba muerto el cadáver?

¿Lavó el cadáver?

¿Le cerró ambos ojos?

¿Enterró el cuerpo?

¿Lo dejó abandonado?

¿Le dio un beso al cadáver?

Cuando miramos un espejo, pensamos que la imagen que nos ofrece es exacta. Pero si te mueves un milímetro, la imagen cambia. Ahora mismo, nosotros estamos mirando a un círculo de reflejos sin fin. Pero a veces, el escritor tiene que destrozar el espejo - porque es, en el otro lado del espejo, donde la verdad nos mira a nosotros.

Creo que, a pesar de las enormes dificultades existentes, una firme determinación, inquebrantable, sin vuelta atrás, como ciudadanos, para definir la auténtica verdad de nuestras vidas y de nuestras sociedades es una necesidad crucial, que nos afecta a todos. Es, de hecho, una obligación.

Si una decisión como ésta no forma parte de nuestra visión política, no tenemos esperanza de restituir lo que casi se nos ha perdido - la dignidad como personas. 